\title{
Unsettling Discourses of Cultural Competence
}

\author{
Karen Sinclair
}

Karen Sinclair is an Aboriginal educator who currently teaches undergraduate and postgraduate courses in Aboriginal studies within the School of Creative Industries at the University of South Australia. Her PhD explored early years educators' understandings and perspectives of cultural competence. Research interests include Aboriginal knowledges in curriculum, Aboriginal early childhood education, Aboriginal research methodologies, critical race theory, and transformative pedagogies. Email: Karen.sinclair@unisa.edu. $\mathrm{au}$

Discourses on cultural competence are fraught with complications and there are concerns about the hidden assumptions behind the construct of cultural competence. This article draws on poststructuralist theories to demonstrate how educators can confront and challenge prevailing discourses of cultural competence by enacting an ethics of resistance. Enacting an ethics of resistance and working in harmony with Aboriginal families and communities challenges and disrupts dominant "regimes of truth" and constructions of cultural competence that sometimes work to disadvantage groups of people. This paper is a provocation for educators to construct counter-discourses to current conceptualizations of cultural competence.

Key words: cultural competence; regimes of truth; discourse; ethics of resistance

\section{Background}

The history of Aboriginal education in Australia has been profoundly shaped by exclusion and disadvantage (Partington, 1998; Price, 2012). It has become common practice to peruse reports on Aboriginal education that focus on "Indigenous disadvantage" and what the Aboriginal child cannot do. As a signatory to the United Nation Convention on the Rights of the Child (1989), Australia has a commitment to ensure that all children's rights and needs are at the centre of policy development and service delivery. The Australian Early Years Learning Framework (EYLF) additionally highlights the significant role of children's rights in the provision of quality teaching and learning in the early years. The EYLF states:

Early childhood educators will reinforce in their daily practice the principles laid out in the United Nations Convention on the Rights of the Child. The Convention states that all children have the right to an education that lays a foundation for the rest of their lives, maximises their ability, and respects their family, cultural and other identities and languages. (Australian Government Department of Education, Employment, and Workplace Relations, 2009, p. 5)

Consequently, the "Journey for Educators: Growing Competence in Working with Australian Aboriginal and Torres Strait Islander Cultures" is identified in the EYLF as a pedagogical practice that encourages educators to develop their cultural competence (Australian Government Department of Education, Employment, and Workplace Relations, 2010, pp. 24-29).

This article draws on the author's doctoral research that used poststructuralist approaches to explore early years educators' understandings and perspectives of Aboriginal and Torres Strait Islander cultural competence (Sinclair, 2017). This article argues that dominant discourses of cultural competence generate an "authoritative consensus about what needs to be done ... and how it should be done" and is represented as a regime of truth (Foucault, 1980) that at times does not benefit Aboriginal children. This paper demonstrates how poststructuralist approaches can challenge dominant ideologies and practices and work to reject explanations of cultural competence that at times 
rely on representations of Aboriginal people as needing remedial assistance. The next section demonstrates how colonial education had a devastating impact on Aboriginal children and communities and contributed to various deficit discourses about Aboriginal children. Second, using a poststructuralist lens, various representations of cultural competence are explored. The last section considers how we can move away from using a regulatory approach to cultural competence toward a more nuanced approach that ensures a multiplicity of perspectives can be explored and critiqued.

\section{Regimes of truth in education}

Prior to colonization, Aboriginal people all over Australia maintained complex social, political, and cultural kinships systems that incorporated a diversity of customary laws, lore, and learning that were underpinned by their Dreaming, kinship systems, and connection to land (Burridge \& Chodkiewicz, 2012, p. 11). Aboriginal society was based on an egalitarian system that was holistic and emphasized belonging, spirituality, and relatedness (Martin, 2005). Learning was viewed as a natural holistic process where education was centred on the land and children learned alongside adults. Prominent Australian Aboriginal scholar Kaye Price (2012) affirms that "right from the beginning there was a specialized education and for each child there was a teacher, a mentor and a peer with whom to learn ... who ensured that history and the essentials of life were taught" (p. 4). Under colonization, education was provided with the main emphasis being on civilizing Aboriginal people, "to teach them Christianity and the Western way of life and to rescue them from their heathen ways" (Partington, 1998, p. 33). Aboriginal children were commonly described as "uneducable," "primitive," and "doomed" (Price, 2012). This type of racialized discourse functioned to position Aboriginal children as inferior as compared to the Western norm. Several Australian government policies operated to separate, segregate, exclude, protect, and remove Aboriginal children from their families and communities with the intent to erase the visibility of Aboriginal people in society (Burridge \& Chodkiewicz, 2012, p. 12; Bodkin-Andrews \& Carlson, 2016, p. 787).

By way of example, in 1883, the Aboriginal Protection Board in the guise of "protecting" Aboriginal people segregated Aboriginal people on missions and reserves. On these missions and reserves, Aboriginal children were required to attend schools administered by missionaries (Burridge \& Chodkiewicz, 2012, p. 13). Part of this education was the enforcement of rules that prohibited Aboriginal children from speaking their home languages and practicing their cultural customs, along with the enforcement of strict regulations that restricted their movements. Reserves, missions, and schools were all institutions in which discipline was enforced. The policies that forced Aboriginal peoples onto reserves and mission were acts of what Michael Foucault referred to as governmentality. Foucault (2003) explained that power works through government to support disciplining mechanisms, such as the role and functions of the Aboriginal Protection Board that forced a population to abide by the dominant ways, in this case, Western ways of living, being, and knowing. Such powers were expressed and applied "through permanent mechanisms of surveillance and control” (Foucault, 2003, p. 37). Based on theories of social Darwinism, it was assumed that Aboriginal people were uneducable. During the 1930s, anthropologist A. P. Elkin asserted the following ideas:

The recent policy is to educate aborigines [sic] (mostly mixed-bloods) up to what might be called a "useful labourer's standard", for to do more, if it were possible, would not help them. Aborigines (full and mixed blood) should not, and cannot, be assimilated by the white community. They must live apart. They cannot become equals of the white race. (as cited in Gray \& Beresford, 2008, p. 205)

Elkin's words reflect the popular belief that Aboriginal people were uneducable because of their "race" (Price, 2012). This demonstrates that the power of language is significant and plays a role in not only perpetuating, as demonstrated in the quote above, but also maintaining a deficit ideology toward the perceived "failure" of 
Aboriginal children. Purdie and Buckley (2010) note that a discourse of deficit is where individual, family, and cultural factors are blamed for the apparent nonachievement of Aboriginal children in education. Furthermore, the apparent discrepancy in educational outcomes between Aboriginal and non-Aboriginal students has come to be viewed as normal (Gillan, Mellor, \& Krakouer, 2017; Vass, 2012). Numerous approaches and policies have been enacted and developed to improve the educational outcomes of Aboriginal children, and there appears to have been some minor improvements over the last few decades. By way of example, there has been a clear move from blatant assimilationist policies to notions of culturally competent and responsive teaching. However, this article argues that discourses of cultural competence continue to perpetuate negative outcomes for Aboriginal students, with consequences in all areas of education, including influencing educators' perspectives of Aboriginal children and education. Foucault (1980) proposed that when discourse becomes dominant, it gains a sense of acceptability and status as being "normal." Discourses then have real effects, legitimating practices alleged to constitute "truths" about "reality" (Malson, 1998, p. 27).

As an illustration, Lynn Cohen (2008) uses a Foucauldian lens to analyze the numerous discourses in the universal "developmentally appropriate practice" (DAP) document endorsed nationally and internationally by the (U.S.) National Association for the Education of Young Children (NAEYC). NAEYC developed this framework as a structure and set of principles and guidelines for best practice in the care and education of young children from birth to age eight. Considering Foucault's (1980) regimes of truth, discourse/power/knowledge nexus, and "institutional apparatus," Cohen (2008) insists that the DAP document as "truth" has been woven together by the "regime" (NAEYC) to regulate what is held to be normal and appropriate for all children and governs early years educators' practices. This "truth" (DAP) fails to consider Aboriginal views of childhood development and the effects this discourse and practice have on the development and well-being of Aboriginal children. This in effect demonstrates how Western models of child development neglect to consider Aboriginal worldviews on child development (Martin, 2008). Similarly, the concept of quality is assumed to be "objective, real, knowable" (Dahlberg, Moss, \& Pence, 2007, p. 4). This raises questions as to whose truth is being advocated and further demonstrates how relations of power are established, consolidated, and circulated through various discourses that function as truth (Foucault, 1980).

Interestingly, the self also plays a significant role in the construction of discourses. Burman, Kottler, Levett, and Parker (1997) affirm that the self faces many competing discourses, and individuals take different positions that are determined by one's understandings at any given time. A Foucauldian approach views the self as continually being positioned within a divided discursive space. There is a presumption that "cultural competence" and all it entails is measurable and consistent. Therefore, it is important to contextualize and position cultural competence within larger contexts of how power, institutions, and our everyday pedagogical practices work to not only create but also maintain "difference" through binary discourses (Castagno, 2014, p. 119). The EYLF, and its emphasis on cultural competence as a pedagogical practice, can be viewed as a vehicle to endorse a deficit discourse of Aboriginal students within early childhood education, as demonstrated in the following quote from the Australian government that cultural competence is "much more than awareness of cultural differences. It is the ability to understand, communicate with and effectively interact with people across cultures" (Australian Government Department of Education, Employment, and Workplace Relations, 2010, p. 16). I argue that a discourse of difference normalizes binaries and perpetuates an "us and them" approach. This discourse is entrenched in a standpoint that normalizes the status quo by "othering" groups that are not perceived as the norm (Castagno, 2014, p. 81). The following section explores further the various discourses of cultural competence. 


\section{The various connotations of cultural competence}

Cultural competence is described in the EYLF as "the ability to interact respectfully, constructively and positively with children, families, staff and community" (Australian Government Department of Education, Employment, and Workplace Relations, 2010, p. 21). Furthermore, The EYLF requests that "we all strengthen our cultural competence" (p. 21). There is no consensus as to the meaning of cultural competence and the concept is interpreted in a myriad of ways. However, as advocated by the EYLF, it is an "evolving concept and our engagement with it will contribute to its evolution" (p. 21). However, it is important to disrupt various discourses of cultural competence because the various discursive repertoires related to cultural competence can do little more than reaffirm the colonial view that "Aboriginality ... [is] a problem to be solved" (Dodson, 1994, p. 3). It has already been ascertained that the language we use shapes and directs how we look at and understand the world (Dahlberg et al., 2007, p. 31). Furthermore, the previous section highlighted how discourse can legitimize certain knowledges as regimes of truth (MacNaughton, 2005). There is a broad assumption that there is an entity or essence of cultural competence that is knowable and is a truth to be defined and described (Dahlberg et al., 2007, p. 93). Our ways of naming things and talking about them produce discourse that can have tremendous influence on our everyday experiences of the world and our relationships with each other (Dahlberg et al., 2007, p. 31). For this reason, it is important to unsettle understandings and perspectives of cultural competence and question who it disadvantages or excludes.

The discourse of cultural competence is treated as an "expert-defined specification" while there is little focus on the constructions of cultural competence (Dahlberg et al., 2007, p. 94). In reviewing the research on cultural competence, there are multiple perspectives and criticisms of cultural competence (Dean, 2001; Lum, 2011; Morris, 2010). This highlights that there is lack of understanding around cultural competence and what it means in practice. Correspondingly, Zofia Kumas-Tan and her colleagues (2007) state that there are some "highly problematic assumptions about what constitutes cultural competence" (p. 548). Cultural competence can be viewed as a list of dos and don'ts and a checklist of culturally appropriate practices that need to be mastered. The problem with this approach is that it does little more than perpetuate stereotypes and essentialize culture. Adding to this, cultural competence has been referred to as the "integration and transformation of knowledge about individuals and groups of people into specific standards, policies, practices, and attitudes ... [leading to] better outcomes" (Dornoo, 2015, p. 81). Terry Cross and colleagues (1989) provide a more widely used definition of cultural competence as:

a set of congruent behaviours, attitudes, and policies that come together in a system, agency or among professionals and enable that system, agency or those professionals to work effectively in cross-cultural situations. (p. 189)

There is clearly confusion as to what cultural competence is, particularly at agency, organizational, and individual levels. However, adding to this dilemma, Cross et al. acknowledge the important task of the individual in "recognizing the cultural complexity and rich diversity that exists among minority populations" (Cross et al., 1989 , p. iii). Here, reference is made to minorities, and later the authors state that cultural competence "assures appropriateness of care for minority populations" (Cross et al., 1989, p. vii). The definition put forth by Cross et al. is widely referred to both nationally and internationally; however, it was developed in the USA as a response to the health inequalities experienced by children of "marginalised and minority populations" (Sherwood \& RussellMundine, 2017, pp. 139-141). Although their work is directed toward an audience within a particular time and context, it has laid the foundations for understanding cultural competence globally. Within the Australian context, it is important to be mindful to contextualize any cultural competence framework in response to community needs (Cleland, Fredericks, \& Watson, 2012, p. 117). Implementation of any cultural competence framework requires input by the local Aboriginal community the proposed framework intends to serve. This is also highlighted by Cross et al. (1989), who emphasize the requirement to respond to the "unique needs of populations whose cultures 
are different than that which might be called "dominant" or "mainstream"'” (Cross et al., 1989, p. 3). The EYLF also draws on the definition provided by Cross et al. (1989, p. 1). However, there is a concern about the hidden assumptions behind the construct of cultural competence. As a social construct it operates to position the "other" as different, as demonstrated in Cross et al's definition where the status quo is maintained through a discourse of difference.

The concept of cultural competence can be problematized and the ability to be completely "competent" questioned (Kirmayer, 2012). A review of cultural competence in the early years literature (Australian Government Department of Education, Employment, and Workplace Relations, 2009, 2010; Secretariat of National Aboriginal and Islander Child Care, 2012, 2013) reveals that cultural competence is an important component in early childhood education. Conversely, the EYLF describes cultural competence as "being aware of one's own world view; developing positive attitudes towards cultural differences; gaining knowledge of cultural practices and world views; and developing skills for communication and interaction across cultures" (Australian Government Department of Education, Employment, and Workplace Relations, 2009, p. 16). However, the description does very little to provide insight into the intricacies of individuals interacting with cultures other than their own. Nor does it encourage individuals and institutions, including early childhood services, to investigate and challenge existing racialized structures and practices that work to disadvantage groups of people. Furthermore, the EYLF reinforces existing stereotypes about the "other." By way of an example, the EYLF affirms that

educators who are culturally competent respect multiple cultural ways of knowing, seeing and living, celebrate the benefits of diversity and have an ability to understand and honour differences. (p. 16)

A poststructuralist and Foucauldian lens highlights the discourse of difference evident in the above quote. Indeed, cultural competence that is framed within a discourse of the "disadvantages borne by minority groups-not in the advantage of dominant group membership" (Jensen, 2005, p. 551) fails to address power and privilege. Current frameworks espousing cultural competence require a "critical understanding of the underlying socio-political and economic processes of power, privilege and institutional racism that create, support and maintain ... disparities" (Rajaram \& Bockrath, 2014, pp. 82-83). Rajaram and Bockrath (2014) point to a limitation related to more than just interrogating our worldviews but more to investigating and challenging "existing racial and cultural structures" (p. 84). Glenda MacNaughton (2005) highlights that an examination of the discourse that is prevalent within the various connotations of cultural competence leads to the necessity of an approach that directs educators to think critically, to challenge inequitable discourse and "to begin to disrupt the regimes of truth that govern the field of early childhood by ... learning to read for equity" (p. 117).

\section{Unpacking competence}

Various connotations of cultural competence maintain the concept as a competency-driven discourse. This framing is problematic because, as Jonathan Morris (2010) argues, "competence imparts the perception that culturally competence/sensitive/responsive practice is indeed attainable if appropriate steps are followed, requisite knowledge is acquired, and the boxes are ticked" (p. 319). Morris adds that the term competence offers nothing more than "a sense of absoluteness, certainty, and clarity, invoking ideas of mastery, proficiency, and efficacy" (p. 319). Such discourse maintains implicit social and institutional directives regarding the positioning of a group of people. Jennings, Bond, and Hill (2018, p. 109) reiterate this argument, raising concerns that some connotations of cultural competence can produce homogenized and stereotypical representations of Aboriginal culture.

The idea of being competent can be challenged, largely because of its association with the idea of reaching a set of competencies that signifies that no further development is required. By way of example, Kumagai and Lypson (2009) 
assert that the problem with the concept of competence in education is that "competencies are often categorized into learning outcomes involving knowledge, skills, and attitudes to allow for educational approaches which address each of these areas" (p. 783). White (2007) affirms that "the assumption that the complexity of practice ... can be adequately conceptualised and measured by discrete 'outputs' like knowledge, skills, and attitudes can be highly problematic" (p. 230). Culture is too multifaceted to suggest that there is a set of competencies that can be defined, tested, and measured and that an endpoint is achievable. Adding to this, when cultural competence is presented as a competency, it not only objectifies Aboriginal cultures but also accentuates a power dynamic between the "expert" and the "other." Discourse surrounding Aboriginal and Torres Strait Islander cultural competence asserts a "relationship 'about' Aboriginal people" and is at most times "defined and inscribed by non-Aboriginal people" (Martin, 2009, p. 67). Consequently, cultural competence is not an ideal to be achieved and instead of competence one should think of gaining understanding as it is nearly impossible to "become competent at the culture of another" (Dean, 2001, p. 624).

It has been established that cultural competence is a multifaceted construct. Australian Aboriginal scholar Mark Rose (2013) asserts that the concept of cultural competence has "gained a life of its own without ever having gone through any semblance of a vigorous intellectual interrogation of what it is" (p. 1). Further to this, the concern is that when terms such as cultural competence, competencies, and diversity are cited in terms of educational missions, it becomes a way of "imagining organisations as having certain attributes" (Ahmed, 2009, p. 44). What is required, write Gunilla Dahlberg and colleagues (2007), is "a dialogic and negotiated process" (p. 94) to coconstruct understandings of cultural competence in partnership with Aboriginal children, families, and communities. However, there remains uncertainty and a degree of ambiguity surrounding the concept of cultural competence. The question remains: When working toward achieving equitable outcomes, is cultural competence a helpful construct? Adding to this question, and in line with the work of Sara Ahmed (2012), what does it mean to embody cultural competence?

\section{Applying an ethics of resistance}

The previous sections have pointed to the dichotomy between what constitutes cultural competence and assertions that cultural competence is an attainable measure (Kumas-Tan et al., 2007, p. 548). It has also been revealed that the ongoing legacy of colonial, political, discriminatory, and racialized discourse has dominated and determined policy making in education through generations (Gray \& Beresford, 2008). Foucauldian concepts have illuminated how we need to challenge reductive notions that suggest one can "know" and "be competent" and proficient in a culture. Therefore, it is important for educators to continually examine and problematize assumptions around the meanings of influential concepts. Rose and Khan (2013) suggest that a significant flaw in promoting cultural competence is programs or workshops that offer "little pedagogical extensions on workplace translation" (p. 11). Engaging in dialogue offers the possibility of better identifying and interrogating discourses of truth and knowledge. Extending this idea, Furlong and Wight (2011) argue that the term cultural competence lacks conceptual coherence; therefore, they encourage one to work from a place of curiosity and "informed not knowing" (p. 39).

Extending this idea, Cave, Connerton, Honig, and Robertson (2012, p. 60) suggest creating a "space of encounter" where educators have opportunities to share and exchange wonderings and knowledge to enable new understandings to emerge. Such a space may provide opportunities for educators to critically reflect on their own assumptions and the fixed meanings they may encounter, as well as to seek creative ways to open dialogue to "embrace their own moments of not-knowing" (Pacini-Ketchabaw \& Nxumalo, 2012, p. 270). As we encounter this space, we struggle with concepts and meanings, but through dialogue and critical self-reflection may move to a new way of doing that produces new lenses to stretch our thinking beyond the regimes of truth that currently construct 
our understandings (Harvey \& Russell-Mundine, 2018). Furthermore, developing intentionality in our practice is important. Specifically, educators need to act intentionally and journey toward ways of doing transformative work through enacting an ethic of resistance, defined by Hillevi Lenz Taguchi (2006) as

conscious acts of thinking deeply about the assumptions and taken-for-granted notions we bring with us (often without awareness) as we engage in our daily work with children. As we practice an ethic of resistance, we deconstruct, or take apart, what we "know to be true," to reflect on it, analyze it, criticize it, and resist its seductive powers arising from its familiarity. (p. 259)

An ethic of resistance to confront and critically reflect on inequitable pedagogies and assumptions-what I refer to as upsetting racialized blind spots-is crucial. When we are confronted with racialized practices, "we are called to respond-although knowing how to respond can be unsettling” (Cheeseman \& Kocher, as cited in Fleet, Patterson, \& Robertson, 2012, p. 304). Navigating around these blind spots can be uncomfortable and they are rarely discussed by educators, but it is vital to challenge regimes of truth that contribute to racialized practices. Such an approach makes sense given that many curriculum initiatives claim to be a solution to the various failings of the education system (Maxwell, Lowe, \& Salter, 2018, p. 11). Nicholas Burbules (2002) refers to educators undertaking a shared quest of developing knowledge and understanding and argues that

whenever any pedagogical practice or relation becomes "naturalized" and comes to be seen as the only possibility, the best possibility or the most "politically correct" possibility, it becomes an impediment to human freedom, diversity, exploration, and-therefore-the possibilities of learning and discovery. (p. 266)

The above quote points to the importance of deconstructing understandings related to authoritative constructions of cultural competence. To put it another way, questioning our ways of knowing turns our attention to move beyond a normalized way of responding and instead open ourselves to many possibilities to shift from understanding cultural competence to complexifying cultural competence (Pacini-Ketchabaw, Nxumalo, Kocher, Elliot, \& Sanchez, 2015, p. 21). This view aligns with Rhymes and Brown (2005), who state that "cultural competence is not simply a skill set to be taught but involves a fundamental shift in the way one perceives the world. It is more a path on which to travel, versus an end to be achieved" (p. 1). Applying an ethic of resistance can disrupt both unequal power relationships and deficit discourse. However, this disruption can only occur in relationship with other people. Working with Aboriginal families and communities conveys to the families appreciation of and valuing of their ways of knowing, being, and doing (Martin, 2008). Establishing these relationships is vital, not only for Aboriginal parents, families, and communities, but for all stakeholders. As we work together to disrupt regimes of truth about cultural competence, we realize that we can never totally see the world from the viewpoint of another, but we can be open to disrupting our present understandings and be receptive to other narratives through authentic encounters. This process must incorporate principles of respect, reciprocity, trust, and understanding, all of which underpin Indigenous epistemologies and ways of doing.

\section{Conclusion}

The early years literature highlights several recommendations for educators to be "culturally competent" (Australian Government Department of Education, Employment, and Workplace Relations, 2010; Secretariat of National Aboriginal and Islander Child Care, 2013). However, there continues to be a degree of ambiguity surrounding the term. Adding to this ambiguity, the legacy of colonization in Australia has contributed to and significantly impacted education and continues to influence education systems today. This article has highlighted that Aboriginal people were exploited and oppressed through various policies and practices. It has also demonstrated that the concept of 
cultural competence is a construct that has been developed to magnify a lens on Aboriginal cultures as something that can be known about. Such understanding then becomes discourse, which then becomes a "truth." Foucault's (1980) notion of governmentality can be used to critique the ways in which government policies and curriculum frameworks have been applied to regulate the behaviours of educators and children and how systems operate to sustain an assimilatory political agenda. The use of Foucauldian concepts permits deconstruction of language and discourses related to cultural competence that contribute to racialized discourses that essentialize Aboriginal cultures. Furthermore, a poststructuralist and Foucauldian lens has valuable potential to help educators turn the gaze upon themselves, to view the self as an active participant in a pervasive ideology that works to justify domination of one group over other groups (Castagno, 2014). There is hope that educators can move beyond a normalized way of responding to institutional directives toward cultural competence and enact an ethic of resistance to facilitate ways of knowing, being, and doing cultural competence in partnership with local Aboriginal communities.

This article has highlighted the urgent need to critique and reframe understandings of cultural competence. Reframing the discourse of cultural competence should occur through relationships and dialogue with Aboriginal communities, first as a matter of respect, and second to provide us with an ethical compass with which to navigate the multifaceted construct of cultural competence. This suggestion is in line with Pease's (2002) idea that there is a need to "challenge the status of [our] own professional knowledge and consider the extent to which [our] narratives retain traces of dominant discourses" (p. 142). Together with Aboriginal families and communities, we can work collaboratively to construct counter-discourses about the concept of cultural competence that privilege Aboriginal narratives about cultural competence. The aim of this paper is to not suggest solutions nor discard the notion of cultural competence altogether, but to provoke educators to consider current conceptualizations of cultural competence and question how we might work with Aboriginal families and communities to reconceptualize new thinking about cultural competence. 


\section{References}

Ahmed, S. (2009). Embodying diversity: Problems and paradoxes for Black feminists. Race Ethnicity and Education, 12(1), 41-52. https:// doi.org/10.1080/13613320802650931

Ahmed, S. (2012). Diversity: Problems and paradoxes for Black feminists. In Y. Taylor (Ed.), Educational diversity (pp. 203-218). London, UK: Palgrave Macmillan.

Australian Government Department of Education, Employment, and Workplace Relations. (2009). Belonging, being, and becoming: The early years learning framework for Australia. Retrieved from https://docs.education.gov.au/node/2632

Australian Government Department of Education, Employment, and Workplace Relations. (2010). Educators belonging, being, and becoming: Educators' guide to the early years learning framework. Commonwealth of Australia. Retrieved from http://files.acecqa. gov.au/files/National-Quality-Framework-Resources-Kit/educators_guide_to_the_early_years_learning_framework_for_australia.pdf

Bodkin-Andrews, G., \& Carlson, B. (2016). The legacy of racism and Indigenous Australian identity within education. Race Ethnicity and Education, 19(4), 784-807. https://doi.org/10.1080/13613324.2014.969224

Burbules, N. C. (2000). The limits of dialogue as a critical pedagogy. In P. Triofonas (Ed.), Revolutionary pedagogies (pp. 251-273). New York, NY: Routledge.

Burman, E., Kottler, A., Levett, A., \& Parker, I. (1997). Power and discourse: Culture and change in South Africa. In A. Levett, A. Kottler, E. Burman, \& I. Parker (Eds.), Culture, power and difference: Discourse analysis in South Africa (pp. 1-14). London, UK: Zed Books.

Burridge, N., \& Chodkiewicz, A. (2012). An historical overview of Aboriginal education policies in the Australian context. In N. Burridge, F. Whalan, \& K. Vaughan (Eds.), Indigenous education: A learning journey for teachers, schools, and communities (pp. 11-21). Rotterdam, The Netherlands: Sense.

Castagno, A. E. (2014). Educated in whiteness. Minneapolis: University of Minnesota Press.

Cave, L., Connerton, B., Honig, T., \& Robertson, J. (2012). Get over yourself: The ethics of respect. In A. Fleet, C. Patterson \& J. Robertson (Eds.), Conversations: Behind early childhood pedagogical documentation (pp. 60-73). Mt. Victoria, Australia: Pademelon Press.

Cleland, A., Fredericks, B., \& Watson, I. (2012). Cultural competence in Indigenous Australian social work: What's needed in preparing human service practitioners to work effectively with Indigenous Australian people? In D. Hikuroa (Ed.), Proceedings of the International Indigenous Development Research Conference 2012, Ngā Pae o te Māramatanga, New Zealand's Indigenous Centre of Research Excellence, Auckland, June 27-30.

Cohen, L. E. (2008). Foucault and the early childhood classroom. Educational Studies, 44(1), 7-21. https://psycnet.apa.org/ doi/10.1080/00131940802224948

Cross, T., Bazron, B., Dennis, K., \& Isaacs, M. (1989). Towards a culturally competent system of care, vol. 1. Center for Child Health and Mental Health Policy, Georgetown University Child Development Center, Washington, DC.

Dahlberg, G., Moss, P., \& Pence, A. (2007). Beyond quality in early childhood education and care: Languages of evaluation ( $2^{\text {nd }}$ ed.). London, UK: Falmer Press.

Dean, R. (2001). The myth of cross-cultural competence. Families in Society: The Journal of Contemporary Social Services, 82(6), 623-630. https://doi.org/10.1606\%2F1044-3894.151

Dodson, M. (1994). The end in the beginning: Re(de)finding Aboriginality. Australian Aboriginal Studies. The Wentworth Lecture, 30 June. Retrieved from https://aiatsis.gov.au/sites/default/files/docs/presentations/1994-wentworth-dodson-michael-end-in-thebeginning.pdf

Dornoo, M. (2015). Teaching mathematics education with cultural competency. Multicultural Perspectives, 17(2) 81-86. https://doi.org/ 10.1080/15210960.2015.1022447

Fleet, A., Patterson, C., \& Robertson, J. (Eds.). (2012). Conversations: behind early childhood pedagogical documentation. Sydney, Australia: 
Pademelon Press.

Foucault, M. (1980). Power/knowledge: Selected interviews and other writings 1972-1977 (C. Gordon, Trans.). New York, NY: Pantheon Books.

Foucault, M. (2003). Abnormal: Lectures at the Collège de France 1974-75 (G. Burchell, Trans.). New York, NY: Picador.

Furlong, M., \& Wight, J. (2011). Promoting "critical awareness" and critiquing "cultural competence": Towards disrupting received professional knowledges. Australian Social Work, 64(1), 38-54. https://doi.org/10.1080/0312407X.2010.537352

Gray, J., \& Beresford, Q. (2008). A “formidable challenge": Australia's quest for equity in Indigenous education. Australian Journal of Education, 52(2), 197-223. https://doi.org/10.1177\%2F000494410805200207

Gillan, K. P., Mellor, S., \& Krakouer, J. (2017). The case for urgency: Advocating for Indigenous voice in education. Camberwell: Australian Council for Educational Research.

Harvey, A., \& Russell-Mundine, G. (2018): Decolonising the curriculum: Using graduate qualities to embed Indigenous knowledges at the academic cultural interface. Teaching in Higher Education, 24(6), 789-808. https://doi.org/10.1080/13562517.2018.15081 31

Jennings, W., Bond, C., \& Hill, P. S. (2018). The power of talk and power in talk: A systematic review of Indigenous narratives of culturally safe healthcare communication. Australian Journal of Primary Health, 24(2), 109-115. https://doi.org/10.1071/PY17082

Jensen, R. (2005) The heart of whiteness: Confronting race, racism and white privilege. New York, NY: City Light Books.

Kirmayer,L.J.(2012).Rethinkingculturalcompetence.TransculturalPsychiatry,49,149-164.https://doi.org/10.11772F1363461512444673

Kumagai, A. K., \& Lypson, M. L. (2009). Beyond cultural competence: Critical consciousness, social justice, and multicultural education. Academic Medicine, 84(6), 782-787. https://doi.org/10.1097/ACM.0b013e3181a42398

Kumas-Tan, Z., Beagan, B., Loppie, C., MacLeod, A., \& Frank, B. (2007). Measures of cultural competence: examining hidden assumptions. Academic Medicine, 82(6) 548-557. https://doi.org/10.1097/ACM.0b013e3180555a2d

Lenz Taguchi, H. (2006). Reconceptualizing early childhood education: Challenging taken-for-granted ideas. In E. Johanna \& J. T. Wagner (Eds.), Nordic childhoods and early education philosophy, research, policy, and practice in Denmark, Finland, Iceland, Norway, and Sweden (pp. 257-287). Greenwich, CT: Information Age.

Lum, D. (2011). Culturally competent practice: A framework for understanding diverse groups and justice issues (4 ${ }^{\text {th }}$ ed.). Belmont, CA: Brooks/Cole.

MacNaughton, G. (2005). Doing Foucault in early childhood studies: Applying poststructural ideas. New York, NY: Routledge.

Malson, H. (1998). The thin woman: Feminism, post-structuralism and the social psychology of anorexia nervosa. New York, NY: Routledge.

Martin, K. (2005). Childhood, relatedness and lifehood: Aboriginal ways of being, knowing and doing. In J. Phillips \& J. Lampert (Eds.). Introductory Indigenous studies in education: The importance of knowing (pp. 27-40). Sydney: Pearson Education.

Martin, K. (2008). Please knock before you enter: Aboriginal regulation of outsiders and the implications for researchers. Flaxton, Australia: Post Pressed.

Martin, K. (2009). Aboriginal worldview knowledge and relatedness: Re-conceptualising Aboriginal schooling as a teaching-learning and research interface. Journal of Australian Indigenous Issues, 12(1), 66-78.

Maxwell, J., Lowe, K., \& Salter, P. (2018). The re-creation and resolution of the "problem" of Indigenous education in the Aboriginal and Torres Strait Islander cross-curriculum priority. Australian Educational Researcher, 45(2), 161-177. https://doi.org/10.1007/ s13384-017-0254-7

Morris, J. (2010). In-between, across, and within difference: An examination of "cultural competence." International Journal of Child, Youth, and Family Studies, 1(3/4), 315-325. https://doi.org/10.18357/ijcyfs13/420102092 
Pacini-Ketchabaw, V., \& Nxumalo, F. (2012). Unpacking racialization through pedagogical documentation: Exploring nomadic practices. In A. Fleet, C. Patterson \& J. Robertson (Eds.), Conversations: behind early childhood pedagogical documentation (pp. 259-272). Sydney, Australia: Pademelon Press.

Pacini-Ketchabaw, V., Nxumalo, F., Kocher, L., Elliot, E., \& Sanchez, A. (2015). Journeys: Reconceptualizing early childhood practices through pedagogical narration. Toronto, ON: University of Toronto Press.

Partington, G. (Ed.). (1998). Perspectives on Aboriginal and Torres Strait Islander education. Katoomba, Australia: Social Science Press.

Pease, B. (2002). Rethinking empowerment: A postmodern reappraisal for emancipatory practice. British Journal of Social Work, 32(2), 135-47. http://hdl.handle.net/10536/DRO/DU:30004128

Price, K. (Ed.). (2012). Aboriginal and Torres Strait Islander education: An introduction for the teaching profession. Cambridge, UK: Cambridge University Press.

Purdie, N., \& Buckley, S. (2010). School attendance and retention of Indigenous Australian students. Issues Paper No. 1. Melbourne: Closing the Gap Clearinghouse, Australian Institute of Health and Welfare.

Rajaram, S. S., \& Bockrath, S. B. (2014). Cultural competence: New conceptual insights into its limits and potential for addressing health disparities. Journal of Health Disparities Research and Practice, 7(5), 82-89. Retrieved from https://digitalscholarship.unlv.edu/ cgi/viewcontent.cgi?article=1306\&context=jhdrp

Rhymes, J., \& Brown, D. (2005). Summary report cultural competence in primary health care: Perspectives, tools, and resources. Dartmouth, NS: Capital Health.

Rose, M. (2013). An almost competent look at cultural competency. Indigenous Voices: Indigenous Global Leadership, 21-32.

Rose, M., \& Khan, G. (2013). AAMT report: Cultural competency evaluation. Adelaide: Australian Association of Mathematics Teachers.

Secretariat of National Aboriginal and Islander Child Care. (2012). Cultural competence in early childhood education and care services: SNAICC consultation overview. North Fitzroy, Australia: Author.

Secretariat of National Aboriginal and Islander Child Care. (2013). A place for culture? Exploring Aboriginal and Torres Strait Islander cultural competence in the National Quality Standard. North Fitzroy, Australia: Author.

Sherwood, J., \& Russell-Mundine, G. (2017). How we do business: Setting the agenda for cultural competence at the University of Sydney. In J. Frawley, S. Larkin, \& J. A Smith (Eds.), Indigenous pathways, transitions, and participation in higher education: From policy to practice (pp. 133-150). Singapore: Springer.

Sinclair, K. (2017). Educators' understandings and perspectives of Aboriginal and Torres Strait Islander cultural competence: A mixed methods study (Unpublished doctoral thesis). School of Communication, International Studies and Languages, University of South Australia.

United Nations. (1989). Convention on the rights of the child. Retrieved from https://www.ohchr.org/en/professionalinterest/pages/crc. aspx

Vass, G. (2012). So, what is wrong with Indigenous education? Perspective, position, and power beyond a deficit discourse. The Australian Journal of Indigenous Education, 41(2), 85-96. https://doi.org/10.1017/jie.2012.25

White, J. (2007). Knowing, doing, and being in context: A praxis-oriented approach to child and youth care. Child \& Youth Care Forum, $36,225-255$. 